\title{
From Drive to Value
}

\section{Brown JW and Zhadiaiev D* \\ New York University Medical Center Fellow, USA}

*Corresponding author: Jason W Brown, MD, PC, Clinical Professor, New York University Medical Center, Fellow, USA, Email: drjbrown@hotmail.com

\section{Conceptual Paper}

Volume 4 Issue 3

Received Date: August 11, 2021

Published Date: September 09, 2021 DOI: $10.23880 /$ phij-16000195

\section{Abstract}

This paper takes up the processual account of drive and its derivations in relation to desire and emotion with an aim to explore the continuity of feeling from internal drive to value in the world. A mental state or act of cognition begins with the impulse and category of instinctual drive; initially hunger, then reproduction. Drive partitions to desire, which is shaped by value. Action conveys feeling; concepts are pre-perceptual. The combined concept/feeling can remain internal as emotion or distribute into action in vocalization or display. The transition in the mental state from drive (need) through desire (want) is constrained by intrinsic value which accompanies the object outward as extrinsic value (worth). Except for value as a continuant of desire into worth, the partly intra-personal nature of action prevents feeling from externalizing. Feeling drives concepts to completion. Concepts propelled by feeling undergo specification to images and/or objects. The feeling in the action gives intensity to emotion; the concept in the perception gives the quality of emotion. Feeling empowers concepts to finality, as emotions, ideas or act/objects. In animal mind, feeling empowers drive-categories. In human mind, feeling distributes as emotion into a diversity of ideas. Feeling unfelt in lower organisms is felt in human mind according to the degree of individuation.

\section{Introduction}

The philosophy of value tends to be concerned with factual judgments in relation to ethical choice, economic worth or adaptive decisions; that is, better and worse, the shoulds and should nots of moral conduct, the classification of things that are good or bad, or value as the outcome of instruction, deliberation and/or an intention to act. Since value can be attributed to subjective preference, feeling, habit and bias without rational justification, indeed, what we value most - family, friends - are of this sort, the account of value shifts from the nature of value itself to the objects of valuation, specifically to an evaluation of the legitimacy of the valuation; that is, the object of the value replaces the valuation of the object. Because they are subjective and weighted with self-interest value-judgments are distinguished from truthjudgments or facts, though it can be argued that facts are the endpoints of valuations. Intrinsic or extrinsic value is conceived as an incentive or a lure to which a judgment is directed. An occasion of decision defines the value to which the decision pertains. The value is realized through its object or application. Value can apply to self-interest, as in avoiding pain and seeking pleasure, or to ethical acts that concern others and involve self-sacrifice. When value is an appraisal of outward worth, it becomes a judgment.

The universality of value in human cognition is such as to limit its application, generally to aesthetic and moral choice as in the value of a good act or a work of art. The object replaces the value, what it is and how it arises. Nor is there agreement on value in nature, whether value is intrinsic to the world or is projected outward by the mind. If value is unique to human mind and its interpretation is confined to art and ethics, the problem remains of its evolution or emergence, similar to that for consciousness. For most philosophers, value pertains to ethical choice. Dewey [1] surveyed the range of its applications and conceded that value begins with impulse, though he focused discussion on evaluative judgements. These can be for what is good for the individual or what is good for others. The balance of the ego- and exo-centric, or the inhibition of self-interest for the good of others, is fundamental to moral choice. Moral values would seem to be uniquely human, while the morality of nature is survival and reproduction, yet human valuations 
are imparted by the animal ancestry.

For philosophers who think of value as a judgment, a rational comparison of good and bad, or better and worse, rather than a feeling, an inclination or a disposition, the same question arises. If value is moral judgment, say the value of truth or the good, where does it come from and how does it develop? When valuation is centered in an act of conscious judgment or in the object of a valuation, for example, the value of a good act, the process through which the valuation arises is diminished. As with other mental phenomena, antecedents become irrelevant once outcomes are clear.

This paper is a speculation on value-creation and its continuity with other mental phenomena. The first question is, what is the origin of value in mind and world? Another approach is whether there is intrinsic value in objects or only in the mind of the observer. Are we drawn to objects of value or do we create value and impose it on them? Do objects have intrinsic value independent of mind? Is value transported to the world or imposed. Does it extend from mind into the concepts out of which objects are specified? In what form, if any, is value or its precursors in physical nature? If we begin with the physical world, do we find the antecedents of human value? If we begin with an evolutionary account of the mind, is it likely that value or its precursors can be found in primitive organism?

The earliest sign of value is interest or preference. To attend or to notice is to value one thing over another; indeed, one could claim that existence itself is the seed of valuation. Does a tropism become a bias, which becomes habitual, which becomes a preference, and finally a conscious desire? The selection of one thing or direction over another is a value. Value entails the consciousness of the implicit choice in preference. We do not value that for which we have no interest, nor do we have interest in things which, for us, are of no value. Interest is an early sign of valuation. This raises the question of how the value that grows out of interest is applied to external objects. Is value, along with feeling and meaning, transported outward through concepts into objects as worth?

If value is limited to conscious judgment, even if it arises in primitive life forms, the dependence on consciousness implies that, as with consciousness, value is either an evolutionary continuant or an emergent. Did value, or consciousness, emerge at a certain point in neural complexity, or does value - proto-value - appear in the lowest of organisms; if protovalue is ingredient in the earliest organisms it would appear at the onset of living systems. The question then arises, does value have its roots in tropisms, preferences and orientations, say in approach/avoidance, or in the attraction to pleasure and aversion to displeasure? If so, how do these inclinations lead to rational judgments? Presumably, value derived as interest or preference carves up the world into events, which in turn evokes beliefs that create facts. Put differently, value selects events about which factual determinations can be made. This is the ground for consciousness of subjective aim and the intervention of reason, and materialism cannot explain this freedom [2]. One can say that certainty in a fact is the endpoint of value-formation.

Value that arises in desire is the wish for a future object or desired course of action. To acquire a valuable object, to feel desire for something one wants, or someone who is loved, a person of incalculable value, is to wish to have or admire an object that is perceived as good or pleasurable. In such instances when the desired object is not present, valuation enters into a decision, whether emotive or rational, as to the best course of action to obtain the desired end. The valuation of means to that end is, from the point of view of the quality of value, a trivial distinction. In cases where there is an immediacy of value in decision - the choice of the right path or response - preference is a pragmatic thread to drive and adaptation. On this way of thinking, value is a direction to the better (more adaptive) of several possible actions.

This paper takes an historical or diachronic approach to the evolution of value and the intra-psychic continuum from value as preference, say for pleasure, as in safety, warmth or food, or for what could be deemed good for the organism, to value as ingredient in desire. Conscious valuation is the outcome of a continuity of feeling that passes outward with objects. Indeed, value is perhaps the only mode of feeling that accompanies the object-development into the world. In the course of this process, the satisfactions of impulse individuate the attenuations of rational thought. The emotive quality of value impels action to what, from the standpoint of the agent, is the most adaptive or reasonable act. Values instilled in childhood are brakes on egocentric conduct, more like generic dispositions than reflective judgments, laying down unconscious habits through which character is effected in behavior. The evolutionary path from energy, as will, through feeling to the pursuit of the good is the selfrealization of an act of cognition in a trajectory from raw impulse to conscious refinement.

\section{Speculation on the Origins of Value}

Value arises in desire as a mode of feeling. If desire is the wish for something, value is the motivation for that wish. Value is the feeling that directs a desire to its object. The beginnings of feeling are surmised to have their onset as a progression from the physical to the animate [3] as a transition from bi-directional energy in inorganic entities to directional feeling in living organisms. Specifically, isotropic energy is presumed to evolve to directional feeling, which is 
the life force that animates organisms. The continuum from energy to feeling and its subsequent evolution to drive are the basis for a pan-protopsychism in which living systems can be traced to the energic underpinnings of physical entities. Directional energy, as feeling, is the basis for growth. In each epoch of existence, feeling propels the entity through one full cycle of being.

How unity develops out of multiplicity, the reconciliation of (a sense of) inner wholeness and the perception of outer diversity, is an old problem in metaphysics. Does mind combine diversity to felt unity in the simultaneity of a mental state? The enfolding of disparate constituents binds them together.

It is not possible to draw a line between things that experience and things that do not if we start from the principles of dualism and materialism. As Macklin, Mathison and Dibben argue on the basis of D.R. Griffin's analysis, time presupposes experience and to experience is to have temporal extension, which is circular position - evolution supposes an existence of time [2].

Temporality entails one-dimensional order in which feeling brings unification. Put differently, the manifold of an aggregate has unity as an event, that is, in process, not as a collection of discrete entities [4]. To paraphrase Whitehead's well-known remark, the many become One (by entrainment in momentary process) and a new One is created. Or in Wordsworth:

"There is a dark

Invisible workmanship that reconciles

Discordant elements, and makes them move

In one society" Prelude: 355

\section{Act and Object: Feeling and Concept}

The history of human mentality makes an important advance in the appearance of instinctual drive. The initial state entails a concentration of feeling and its distribution in the categorical primes that are its objects. The categories are pre-perceptual concepts that lead to objects; the feeling in drive (urge, will) refers to early stages in action that accompany drive-categories. The feeling is inseparable from the drive category which partitions to sub-categories of implementation. For example, hunger as a basic drivecategory individuates to sub-categories of prey, stalking, capture, strategy, feeding and escape. The motility that implements the drive imparts the feeling, whether interest, fear, caution or the savagery of predation. Specifically, the drive-category corresponds to early phases in perceptual development; feeling corresponds to early phases in actiondevelopment. Concepts are static frames innervated by feeling. The dynamic of feeling impels concepts to actualize.
The combined conceptual-feeling transitions through image (thought) and emotion to actuality (Figure 1).

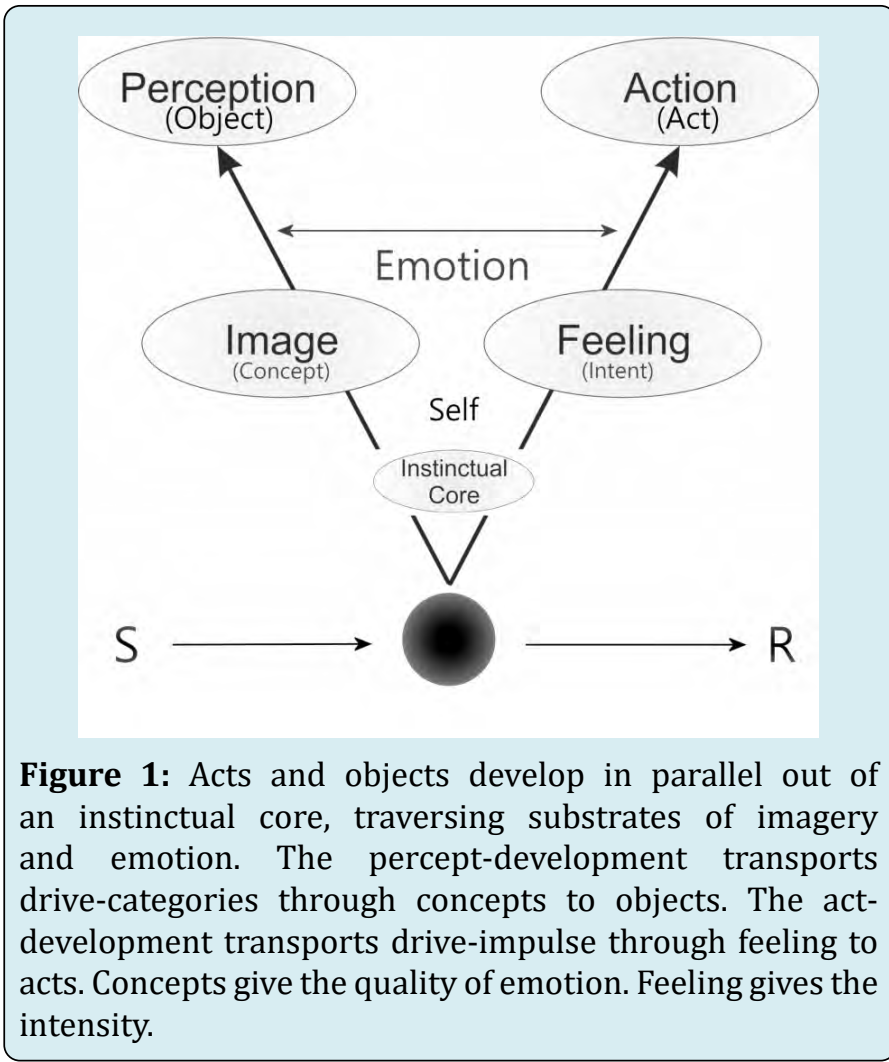

Feeling is realized through action and, like action, remains partly in the mind. The body-image supports early segments in act-generation; even distal limb movement is only partly external. Action retains its locus in mind for the feeling of agent-causation. The feeling of will or drive at an early phase in the derivation of action provides affective intensity in concert with the drive-category. The combined concept and feeling is the source of emotion, generally more intense at earlier (driveclose) phases, and progressively more restrained at distal (thought-close) phases. Actions mediate the feeling that is the dynamic of transition; perceptions mediate the categories or concepts that are its objects. The feeling-tone of developing actions, combined with the conceptual-frame of developing objects, passes through segments of affective intensity to relatively affect-free acts and objects. That is, in human mind, pre-perceptions lay down self and image in a transition to the world; action imbues self and concepts with feeling to energize decision. Feeling is felt as a continuation into action of the implementation of ideas. The main contribution of action to mentality is not the idea or the action plan, which are products of thought and phases in the pre-object; rather, it is the feeling in will or drive, in desire and emotion, in agency, in the distinction of active and passive movement, in the intent and discharge of will in motility and the effectuation of thought as vocal or limb action. 


\section{Philosophy International Journal}

The temporal lag in perception is equivalent to the readiness potential in action. Acts and objects are not outputs and inputs but develop in parallel through endogenous process. Acts are instigated prior to the consciousness of a decision to act, and objects are recognized prior to the conscious perception of what they are. The kernel of an incipient representation at the brainstem core, in conjunction with the diencephalic sources of instinctual behavior, propels action as drive-impulse into pre-perceptual categories. Feeling is the forward-going impulse enacted in bodily space. The lack of full detachment of actions from their subjective antecedents mitigates the outward flow of feeling. The effectuation of emotion in bodily action is display. Put differently, concepts lead to external objects; action leads to discharge in the world. But feeling remains intra-psychic; it appears in gesture because the action, which lays down the emotion, does not, unlike objects, fully detach from mind but is felt as belonging to the agent.

The relation of feeling to action goes back to the debate on Innervationsgefühle between Wundt and James. While awareness of active movement depends on recurrent collaterals of the action discharge, and is thus perceptual, the action-development contributes the feeling that flows into pre-perceptual categories. Specifically, feeling first deposits in drive-categories as instinctual impulse; then, at subsequent phases, it is allocated to drive-derivatives and the concepts of desire. The distribution of feeling into concepts results in emotion, or the affective charge of personal concepts. The distribution of feeling in impersonal concepts, such as ideas, provides the intent or motivation for rational judgment. Reason does not grow out of emotion or the "moral sentiments" (Hume); it is infused and shaped by action-derived feeling as a directional factor. Perception and its preliminaries are static, fixed in the present (or the past realized in the present), while action is forward-looking. Action is clearly engaged when the vectors of drive are innervated, as in flight or fight (below), or when the intensity of emotion spills over from display to energetic action, as in escape, panic or rage. The relation of action to will is the direction of drive-impulse to satisfaction. Will is the impulse of drive carried into the agency of conscious volition.

In sum, the co-temporal development of act and object gives emotion, with arousal of imagery on the pre-perceptual side and, on the action side, an intensity at phases prior to discharge. When feeling discharges into concepts as emotion, except for the primitive drive-based emotions such as panic or rage, its forward-going urge is attenuated. One could say that feeling surrenders impetus when it aligns with a concept. Act and object go on to completion but the activation of earlier segments of thought and feeling combines to give an emotion in which the quality of feeling - what emotion it is - is related to perceptual imagery, and the quantity or intensity of feeling - how strongly it is felt - is related to phases in action discharge. The category or image gives the specificity of the emotion; the action-feeling gives direction and intensity to what is felt. The unity of act and object, or feeling and concept, is the process of becoming, which passes through intermediate segments in mind to actualize in the world.

\section{Drive}

Instinctual drive is the primary reservoir of feeling at the onset of action and the mental state. Feeling concentrates on potential at the inception of the state, initially as hunger (thirst). The urge or will to go forward is the core feeling in action; the categorical-primes of drive are its core concepts. The drive has a conceptual aspect in the category to which it is directed, and an affective aspect in the feeling of directed action. On a recurrence model, such as microgenesis, in which mental states actualize and are replaced, hunger is the primordial self-preservative drive that sustains the organism to replicate itself and, later, to reproduce its likeness in progeny. Hunger is the primary allocation of feeling; it is the generative construct - impulse and category - that leads through thought and emotion to individuation and diversity. Food is the fuel of recurrence; it provides the energy for auto-replication. The initial act of the newborn is to feed, by nursing or other means. The organism first has to survive. Survival is reinstatement. The hunger-drive is in constant recurrence; this is the basis of self-replication. In the wellnourished where food is plentiful, the force of hunger is not felt - "delicacies of taste replace the interest in fullness of stomach" - but in the famished it takes precedence over sexual drive and other needs.

The sexual (reproductive) drive resolves out of hunger, retaining many of its properties; pursuit, aggression, submission and conflicts with rivals, as well as its appetitive and consummatory nature (Figure 2). The urgency of hunger gives way to the intermittency of reproduction. This accompanies a shift from the reinstatement of the individual to reproduction and generic replication. Hunger is essential for causal persistence of the organism, which is auto-replication, while reproduction of progeny is proxy replication. It may be incorrect to refer to the urge to reproduce in animals as a sexual drive; except in animals such as bonobos, it serves primarily for reproduction, not sexual pleasure. In humans, the drive and its evolutionary function have become separated, such that sexuality is dominant. An organism must survive to mate and provide parental care, but all things recur, with the novelty in each occasion a measure of the creativity of organism. One can say, the cycle of life distills to moments of experience continuously repeated. 
Both hunger and reproductive behavior in animals are relatively stereotypical and organized about action, as feeling impels the organism to seek food and mating. In some organisms such as certain birds, the prelude to mating undergoes an extravagant expansion in displays, song and nest-building. Here, the drive is diverted from immediacy to the complex repertoires of reproductive drive. Such preparatory routines no doubt serve an adaptive function though, like the antlers of the extinct elk, far in excess of what should be necessary. In higher animals, the feeling that arises with action pours into primitive emotions; fear, pain and pleasure, and provides the momentum that carries the behavior outward. In humans, of course, under the influence of desire, which is a specification of drive, there is enormous diversity, say as hunger-borne desire leads to culinary habits and sexual desire refines the varieties of sexual pleasure.

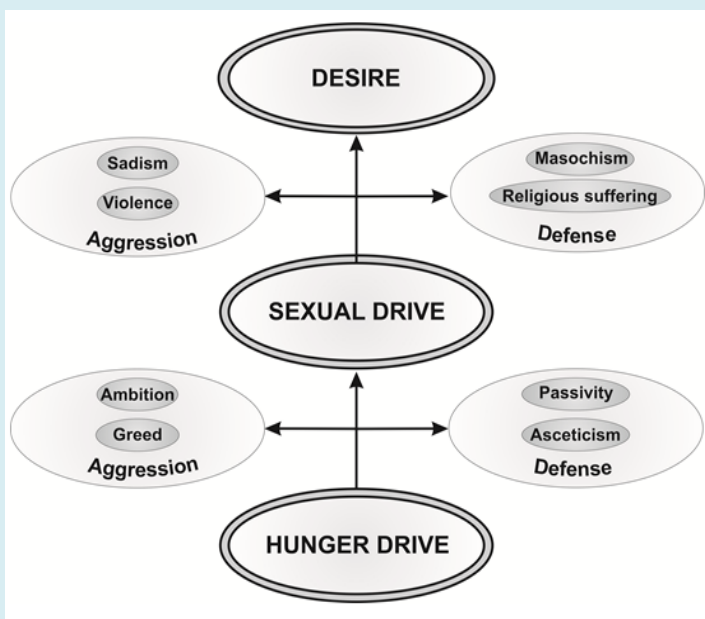

Figure 2: Hunger is directed to aggression and defense, or predation and escape. It individuates to sexual drive, then to desire, with ambition or greed in relation to the aggressive vector and timidity or retreat related to the defensive vector. Hunger partitions to sexual drive which is initially stereotypical, then partitions to desire and the varieties of interests and pleasures derived from the antecedent drives. Drive retains, in desire, the appetitive and consummatory features in the wish and its fulfilment.

Paul MacLean's [5] four F's of drive - fight, flight, feeding and sexual behavior - resolve to two basic drives, hunger (thirst) and reproduction, and the two main vectors of approach and avoidance. The vectors of hunger are predation and defense, seizing prey and avoiding predators. These vectors, along with the hunger drive, fractionate to the sexual drive and its vectors of capture, escape and submission. The primary emotions associated with the basic drives are anger (aggression) and fear. The drives and their vectors are more or less programmatic in relation to categories of limited possibility. Thus, hunger impels a search for what is edible; sexual behavior is restricted, within species, to available and willing females and fortunate or dominant males. The vectors can be conceived as a succession of approach/avoidance behaviors which trace down to paramecia [6].

The constellation of drive-categories and the relation of primitive feeling to concepts - conceptual-feeling - lays down the emotions and is derived to desire and its objects. As derivatives, the emotions show traces of the antecedent drives, though usually mitigated in intensity and more individuated in quality. Thus, greed and ambition can be conceived as partitions of the aggressive vectors of hunger, while timidity and disgust are partitions of the defensive vectors. The sexual drive, which is emphatic when the pangs of hunger are too readily consummated - dinner as a precursor to sex - fractionates to pain avoidance and pleasure seeking, love and loss, affection and grief, and the gradations of sadism and masochism. Fetish and perversion capture nicely the innervation of object-concepts by sexual feeling.

\section{Emotion}

Emotions are most often described as a response to external circumstance. A person is in despair over a loss or the absence of hope; frustrated because of an obstacle or the inability to achieve something; humiliated or proud on some occasion of importance; angry over a setback or disagreement. Affective states are also described in relation to other emotions, such as grief as a form of sadness, sorrow, anguish or as a form of depression, or ascribed to body physiology or chemical alteration in the brain. Fear is a prototypical response to a category of threat, apprehension is unrest about an impending event. Related affects - fright, panic, anxiety - are within the same category. Anger in a category of aggressiveness has rage at one extreme and irritation or annoyance at the other. Love is yet another category, with affection, devotion, passion and ecstasy referring to differing objects, conditions and intensities. Commonly, states overlap; jealousy and envy are distinguished by the need in jealousy for three individuals. The common feature is that emotions are internal states bound to concepts and described in relation to external events, similar states, conditions or categories. Accounts of emotion acknowledge the relation to concepts but for the most part they postulate a reaction to external conditions or an association of feeling and idea. The connection of concept and affect is by way of association [7] or libidinal cathexis (Freud), but not the fractionation of unitary conceptual-feeling into emotions and ideas.

The intensity of an emotion - how strongly it is felt - is related to the concentration of feeling; the quality of the emotion - what emotion it is - can be attributed to the concept. The perceptual event that elicits the emotion does so 


\section{Philosophy International Journal}

by arousing intermediate segments where conceptual phases in the pre-object, together with formative phases of feeling in the action-development, evoke an emotion that is related to the provoking event. On this interpretation, feeling does not combine with concepts - feeling and concept are aspects of a single configuration - but the concept, imported from perceptual experience, together with intermediate phases in action-formation, precipitates as emotion in an intra-psychic field at segments prior to exteriorization. An emotion points to revived and accentuated (neotenous) segments embedded in the final actuality, taking on its qualitative attributes from submerged layers in the inciting perceptual experience, and its quantitative intensity from earlier levels in action. The distinctness of the conceptual content to which the emotion is directed also obtains when feeling pervades an image, whether a memory image or one in the imagination, as in that aroused in expectation. The concept of an emotion is more likely induced by an external event, whereas that of desire tends to be related to a memory image (below).

Many taxonomies of the emotions have been assembled which itemize the emotions without a thought to their explanation. The claim here is that an inciting event, usually but not invariably external, is revived to evoke conceptual phases in the perception of that event, along with corresponding segments in action (feeling), to give specificity and intensity to the emotional state. Feeling in act-formation is the impulse of becoming; concepts in percept-formation prefigure the object that becomes. Put differently, the heightened subjectivity midway in the mental state -feeling derived from drive, concepts derived from instinctual categories - are complimentary aspects of a single configuration - an emotion - that rises into prominence when the dominant focus of the mental state is on earlier segments.

The transition from the necessity of drive, through the subjectivity of emotion to the final actuality encompasses the trajectory of a sequence of mental states, replicated each moment to evoke the imagery in each traversal. The intentional object of an emotion is not merely the external occurrence that appears to be its cause, since people respond differently to comparable events - the death of a close relation can incite joy, grief, relief and so on - but the idea to which the emotion refers and the experiential history that determines the impact of the inciting event.

In mild emotions, feeling is experienced by a self. The self has an emotion, just as the self has a thought. In strong emotions, there is less separation of self and feeling and emotion may consume the mental state. The individual is carried away by the emotion, and may say, I was not myself, lost control or was overcome. The self feels anger, fear or love, but the emotion, when strong, points to an angry, fearful or loving self. In emotional states, the self is hostage to feeling, unable to generate competing thoughts. The implicit relation of self to emotion, and the felt relation of emotion to external events, have an intentional quality that depends on which relation is prominent in conscious experience.

Feeling fills conscious experience when it intensifies or generalizes. When feeling concentrates in one emotion, the concept recedes in the background. Intensity of feeling overwhelms the concept that determines what the feeling is about. In abstract or impersonal concepts, feeling is reduced. Emotion weakens when the concept dominates. Reason does not seek mastery of the emotions. There is no battle of intra-psychic faculties. Feeling wanes as concepts grow more abstract or complex, and conceptual prominence is diminished when feeling is intense. Feeling will intensify in abstract concepts such as liberty when the concept reduces to slogans that incite passion, and emotions subside when their conceptual frame widens or becomes more intricate. When a love for the one becomes a compassion for the many, the emotion, as Hegel noted, is more like an idea than a feeling; that is, the concept, when too inclusive, is more pronounced than the affect, which is diluted in the expansion. Concepts and theory may produce an 'empty' emotions (e.g. feeling of duty) however, concepts are not likely to multiply or increase an intensity of the emotions, like knowing ten wise doctrines will not make anyone a "tenfold" sage [8].

In sum, the conceptual frame of the emotion - the category - enlarges at the expense of the feeling. Conversely, feeling intensifies at the expense of the concept. One can say the more abstract emerges from the more concrete. In the emergence from concrete to abstract, from the primal emotions to the subtlest and/or most general affect-ideas, intense feeling is drained from the concept and only the subtle, refined emotions remain. The relation of concept to feeling is a miniature of the relation of mind to brain, with concept a mental phenomenon and feeling related to physiology.

Feeling is intrinsic to every concept, and every concept has an affective tone. Absent the concept, feeling has no object. Absent feeling, the concept lacks direction. The directedness of feeling in drive carries action to the aboutness of desire. Aboutness needs the momentum that feeling gives to ideas. It is the aim to definiteness. Feeling is the impetus for decision and its implementation in action. Action provides the direction of intentionality, concepts provide its object; that is, feeling gives the aboutness of the intentional, while the concept is what the intentional is about.

\section{Desire}

The object of emotion extracted from present experience is an idea, or a memory image that is experienced in the 


\section{Philosophy International Journal}

present. The satisfaction of the subjective aim, however, may be postponed indefinitely. Unlike other emotions that are encircled by their object (concept), desire tends to be for something pleasant, or the avoidance of the unpleasant; it points to the potential for subsequent feeling when the intention is realized or the object is possessed. Desire is the sublimation of will transmuted from instinctual impulse to conscious intent. The feeling in desire is two-fold, partly to the pleasure of longing, in which the object is what is wishedfor, and partly to the hope of its acquisition. The concept forecasts the object that desire is hoping for. Desire is a partition of drive that is diluted in consciousness to loosen its grasp on immediacy. Desire connotes a state of wanting. While an external object may or may not be present - one can wish to win the lottery or desire to have what one perceives - desire is present feeling, internal as a memory or thought image, the satisfaction of which is deferred to the future.

In sum, desire retains the appetitive and the consummatory features of the drives from which it arises though with less urgency. Unlike drive, the self is conscious of desire and the desired object, a consciousness of the two stages, the wish and its satisfaction. Desire is the inheritance of drive, with vectors of pleasure-seeking and avoidance of displeasure, the difference being the shift from immediacy to expectation, or need to wish, and the specification of the drive-vectors from a fixed repertoire to a multitude of possibilities. This transition is occasioned by the duration of the present and the arousal of content in the mental state. The direction taken by desire is determined by the value assigned to the desired object.

\section{Value}

Desire differs from other emotions in the priority of value. While the quality and force of emotions reflect the valuation given to the event - as noted, the same or comparable events evoke different emotions in different people - desire is more intimately related to personal valuation. As drive is the urgency of preference, desire is the mitigation of immediacy. Desire enfolds present feeling and the anticipation of future pleasure; value determines the desired object shared with the hoped-for outcome, which is felt as present in longing and in the desirability (worth) of what is longed-for.

There is a continuity in the twofold nature of desire - the wish and its satisfaction - each constrained by value. The need and consummation of unconscious drive becomes the wish for satisfaction of conscious desire. The implicit preference of drive becomes the valuation of desire. The fulfilment of drive is the worth of a desired object aa subjective value becomes objective worth. One would not say of desire as of value that it flows into its object, for the feeling of desire is wanting what is absent or unobtainable. Desire looks to the future. Ordinary emotion does not usually have a quality of futurity; it is felt in the here and now.

Evolutionary constraints involve competition for survival and selection of the fittest. In drive, they specify the best available option. In perception, they involve sensory modeling. In other mental acts, there is selection by annulment, the carving of specificity by inhibition, and elimination of the irrelevant or redundant. There is a parallel between refutation as an explicit methodology and elimination as a tacit pattern. Selection is what remains after all else has been rescinded. The parsing of the many to the one is a general law of mind and nature. In life, value provides a constraint on desires that limits the possibility to realize them. There is a culling of desire by value, and a culling of value by character. In science, value is in the selection of topic, the isolation of problems and the choice of experiments designed to resolve them. The uncovering of fact entails the negation of error, similar to selection by elimination in other modes of cognition.

Value has an intra- and extra-personal complement, the latter the value of to external objects. In desire there is a transition from mind to world in the conveyance of intrinsic value to extrinsic worth. On this interpretation, the distinction of intrinsic and extrinsic value is a transition from value as implicit habit or preference, to value as a conscious desire for something, to value as the worth that is attributed to the something that is desired. One says, I want that because it is valuable or, because it is valuable, I want it. This can lead to uncertainty as to which came first. Did I love him because he was handsome, or did I think he was handsome because I loved him? Value and worth straddle the mind/ world divide. Value is not projected on barren objects but flows outward with the act- and object-formation. The lack of full detachment and the belongingness of action give value an external locus but keep it tethered to the mind. Concepts, however, objectify, leaving emotions behind as subjective phenomena.

Similarly, aesthetic values do not inhere in objects but are implicit in the first impression and subsequently "retrieved". That is, in the interpretation of an art work, tacit knowledge bypassed in the original perception is regained in successive revivals. The beauty or meaning in a work is the latent value that first orients the person to the work, and then recurs in conscious reflection. Unlike emotions that objectify in display, the value of a desired object is a stream of feeling that begins in drive and flows into the actual or imagined object. The derivation of the drive repertoire to conscious desire and its varied manifestations is the main road of affect-development. 


\section{Philosophy International Journal}

In sum, value is intrinsic to desire; we desire what we value. Every act of conscious valuation entails an objectified wish. Value invests the objects that desire is seeking. The initial expression of value is existence, then attention distinguishes one event as important. Value begins with interest as one or more qualities are singled out for attention. To attend to one object at the expense of others - in animal or human mind - is the initial condition of value. Consciousness of interest is awareness of preference, while consciousness of preference takes a tropism to a valuation. At a basic level, value is an expression of preference, but how basic? Is a tropism a proto-value? The preference of frogs for certain insects, or insects for plants, or even the "preference" of plants for sunlight, may support an evolutionary origins of value but eliminates the subjectivity and consciousness essential to the intentionality of human valuation. In human mind, preferences "built in" to behavior such as handedness are not valuations, though when the agent is conscious of the preference it approximates a valuation.

Value in the framework of ethics is intrinsic to the good, but the relation to the good, from a psychological standpoint, is arbitrary. A value-judgment is outside the agent as an external relation. Value assigned to good or positive ends or to outcomes of acts is not relevant to the nature of value itself. Someone can value greed, theft or hurtful pleasures. Ordinary values such as the Golden Rule or love thy neighbor are instilled as other-directed constraints on egocentric drive. The transposition of good and bad to right and wrong - the shift from intent to act - presumes that learned values, modified by experience, are drained of feeling to conform to reason. On this view, values consolidate as settled authority to replace the dynamic of process. Cultural and religious obligations provide added reinforcement. Emotion is not pruned from rational appraisal but returns, in the appraisal, as unconscious feeling.

Value determines the positive or negative valence of the objects that desire is seeking and channels desire to normative ends. It lays down the possibilities through which desire can be realized, the do's, don'ts and social norms by which the drives are shaped. Value is an injunction that carves the possible into the acceptable, constraining acts to conform to education, custom, duty, culture and experience, not as a judgment of good or bad, though it is recruited for this purpose, but as a resolution of the weight of competing interests. Desires express personality tainted by character, values are constituents of character with a trace of personality [9-11].

\section{References}

1. Dewey J (1939) Theory of Valuation. University of Chicago Press.

2. Macklin R, Mathison K, Dibben M (2014) Process Ethics and Business: Applying Process Thought to Enact Critiques of Mind/Body Dualism in Organizations. Process Studies 43(2): 61-86.

3. Brown JW (2014) Feeling. Journal of Mind and Behavior.

4. Faber R (2004) Whitehead at infinite speed: deconstructing system as event. In: Helmer C (Ed.), Schleiermacher and Whitehead Open Systems in Dialogue, Walter de Gruyter, Berlin.

5. MacLean P (1990) The Triune Brain in Evolution. Plenum. New York.

6. Schneirla T (1966) Behavioural development and comparative psychology. Quarterly Reviews in Biology 41(3): 283-302.

7. Lindsley D (1951) Emotions. In: Stevens S (Ed.), Handbook of Experimental Psychology, Wiley, New York, pp: 473-516.

8. Halapsis AV (2020) Man and Logos: Heraclitus' Secret. Anthropological Measurements of Philosophical Research 17: 119-130.

9. Brown J (1988) Life of the Mind. Erlbaum. New Jersey.

10. Brown J (2005) Process and the Authentic Life. Ontos Verlag. Heusenstamm.

11. Weiszaecker V von (1939/1958) Le cycle de la structure. Desclee-De Brouwer, Bruges. 